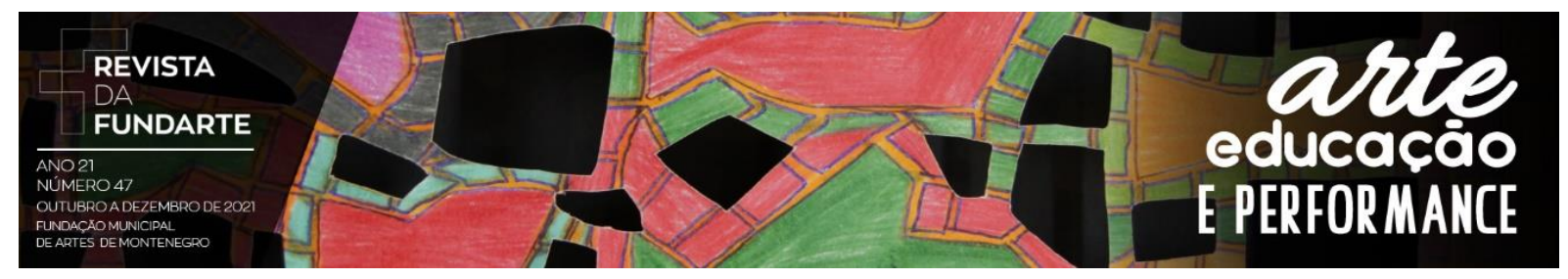

\title{
PORTA QUE COM-PORTA A DANÇA: ABERTURAS PARA A CRIAÇÃO ARTÍSTICA NO ENSINO REMOTO
}

Débora Souto Allemand

Resumo: $O$ trabalho reflete sobre uma proposta artístico-pedagógica realizada na disciplina de Dança no Colégio de Aplicação da UFRGS, em ensino remoto. A partir de elucubrações poéticas sobre a porta, elemento arquitetônico, a atividade de reprodução e criação em dança tinha como intuito a ampliação das capacidades expressivas de estudantes. Ademais, naquele momento a porta pôde ser compreendida como metáfora para a inserção da Dança na escola e também como passagem para outra realidade, diferente daquela pandêmica vivenciada em 2020. Através da tarefa de improvisação em dança, a professora conseguiu compreender parte do contexto e das referências de dança das alunas, bem como foi possível perceber a ampliação de suas possibilidades de criativas.

Palavras-chave: Dança na escola; Improvisação; Criação com objetos.

\section{DOOR THAT HOLDS DANCE: OPENINGS FOR ARTISTIC CRIATION IN REMOTE EDUCATION}

\begin{abstract}
The paper reflects on an artistic-pedagogical proposal realized on Dance subject at UFRGS Laboratory School, in remote education. From poetic reflections on the door, architectural element, the activity of reproduction and creation in dance was intended to expand the expressive capacities of students. Furthermore, at that time, the door could be understood as a metaphor for the insertion of Dance in the school and also as a gateway to another reality, different from the pandemic experienced in 2020. Through the task of dance improvisation, the teacher was able to understand part of the context and references of the students' dance, as well as it was possible to perceive the expansion of their creative possibilities.
\end{abstract}

Key-words: Dance at school; Improvisation; Creation with objects.

Este trabalho integra uma pesquisa em andamento no Programa de PósGraduação em Artes Cênicas da Universidade Federal do Rio Grande do Sul (UFRGS), orientada pela Professora Doutora Vera Lúcia Bertoni dos Santos. Realizada no contexto do Colégio de Aplicação (CAp), Unidade de Educação Básica da UFRGS. A investigação enfoca as possibilidades de inserção da Dança como disciplina autônoma no currículo da Educação Básica. São considerados na pesquisa aspectos políticos, administrativos e pedagógicos da ação docente em Dança (CORRÊA, 2018). 


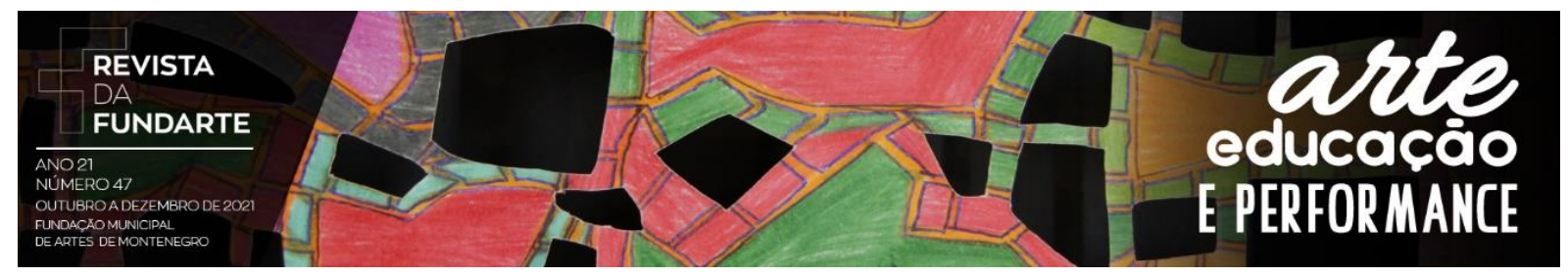

As interações entre eu, professora de Dança do CAp/UFRGS, e a realidade investigada ocorrem na etapa curricular do Ensino Médio no ano de 2020, pautado pelo ensino remoto decorrido em função da pandemia de COVID-191 ${ }^{1}$. O ensino remoto foi iniciado na escola, no final do mês de março, uma semana após a suspensão das atividades presenciais na Universidade. Portanto, diferente de algumas instituições, ou mesmo do ensino de Graduação da própria UFRGS, as atividades educativas aconteceram logo no início do período de distanciamento social.

O ensino aconteceu, então, desde o começo, através de atividades assíncronas em formato de Estudos Dirigidos em PDF, tendo como objetivo principal a manutenção do vínculo de estudantes com a escola. Cada atividade era publicada quinzenalmente e separada por componente curricular no site da instituição e o retorno por parte das alunas ${ }^{2}$ deveria ocorrer diretamente para meu e-mail pessoal.

Dentre as atividades pedagógicas assíncronas propostas na disciplina de Dança, destaca-se uma prática de criação artística que tinha como objetivos proporcionar a compreensão de si na relação do corpo em movimento no espaço e ampliar as capacidades criativas e expressivas, indo ao encontro do que é indicado nas bibliografias e documentos curriculares orientadores da área (BRASIL, 2017; CORRÊA, 2021; LABAN, 1990). As alunas da escola possuíam pouca ou nenhuma experiência em improvisação em dança (LABAN, 1990; SILVA, 2017), especialmente em função da inserção tardia da Dança como componente curricular na escola ${ }^{3}$, que já possuía anteriormente Artes Visuais, Música e Teatro como

\footnotetext{
${ }^{1}$ COVID-19 é uma doença respiratória causada pelo vírus SARS-CoV-2, pertencente à família dos corona vírus, que pode levar a óbito. No Brasil, a Organização Mundial de Saúde decretou, no dia 11 de março de 2020, estado de pandemia.

${ }^{2}$ No Ensino Médio do CAp/UFRGS, cada estudante tem a opção de escolher uma dentre as quatro linguagens artísticas para cursar durante o ano. Assim, opto por utilizar o genérico das pessoas que elegeram pelo componente curricular Dança no feminino, pois, além de constituir uma escolha política de questionamento de normativas hegemônicas, a adoção dessa linguagem tem uma justificativa também quantitativa, visto que a grande maioria dos sujeitos matriculados em Dança em 2020 eram meninas: dos vinte e sete indivíduos, apenas dois eram do gênero masculino.

${ }^{3}$ A Dança como disciplina foi inserida na escola após a nomeação da primeira professora Licenciada em Dança, cuja aprovação se deu mediante concurso regido pelo Edital 08/2018 Magistério da Educação Básica da Universidade Federal do Rio Grande do Sul: Concursos Públicos de Títulos e Provas para a Carreira de Magistério de Ensino Básico, Técnico e Tecnológico para o Colégio de Aplicação. Área: Linguística, Letras e Artes; Subárea: Dança. Disponível em: https://www.ufrgs.br/progesp/?page id=16375. Acesso em: 11 nov. 2019.
} 


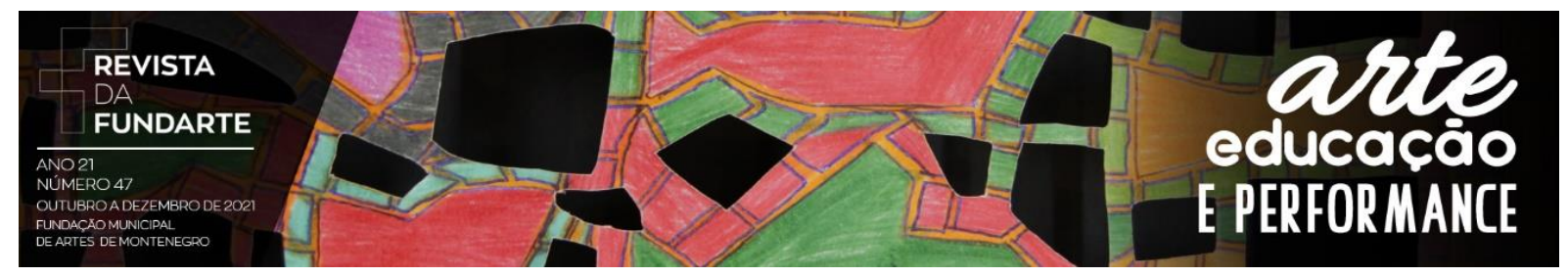

disciplinas autônomas. Desta forma, a proposta artístico-pedagógica de criação em contato com o elemento arquitetônico porta, intitulada "Qual é a porta que me comporta?", mostra-se propícia à reflexão sobre aprendizagem em Dança.

Este texto é calcado na reflexão sobre a prática pedagógica da autora e utiliza dados produzidos nas atividades realizadas por estudantes de Dança do CAp/UFRGS. O uso das imagens, vídeos e depoimentos escritos pelas alunas foi autorizado por elas e pelas pessoas que são suas responsáveis legais, através da assinatura de Termos de Assentimento e de Termos de Consentimento Livre e Esclarecido ${ }^{4}$. Além da reflexão sobre a prática específica de sala de aula, o texto traz relações sobre o período de inserção da Dança na referida escola e sobre o momento da pandemia e do ensino remoto em que foi feita a atividade, pensando na poética das portas como forma de alinhavar esses pontos.

\section{O que é uma porta?5}

Uma porta pode ser compreendida de diferentes formas e pode suscitar diversas questões. Refletindo a respeito das relações performáticas entre corpo, espaço e objetos cotidianos, Almeida Batista e Da Silva (2021, p. 4) sugerem que "pode-se entender que cada objeto existente, para além de sua função, é também um mundo subterrâneo de relações." Assim, em maio de 2020, no momento de proposição da atividade "Qual é a porta que me com-porta?", as portas vinham sendo avistadas não somente como um elemento, um objeto passível de contato para a criação em dança. Para além disso, elas podiam ser compreendidas como um outro corpo, um corpo possível de dançar junto, num período em que o distanciamento social se fazia fundamental. Com isso, a porta era vista não só como um elemento com

\footnotetext{
${ }^{4}$ Parte do material está vinculado à pesquisa "Currículo em Movimento: inserção da Dança no Colégio de Aplicação da UFRGS", aprovada na UFRGS sob o número 38273. O envolvimento de estudantes do Ensino Fundamental e Médio como sujeitos de pesquisa foi submetido à Plataforma Brasil e encaminhado e aprovado pelo Comitê de Ética em Pesquisa do Hospital Ernesto Dorneles, segundo os trâmites de ética em pesquisa com seres humanos.

${ }^{5}$ Os subtítulos deste texto são inspirados ou são citações diretas de Fuão (2016).
} 


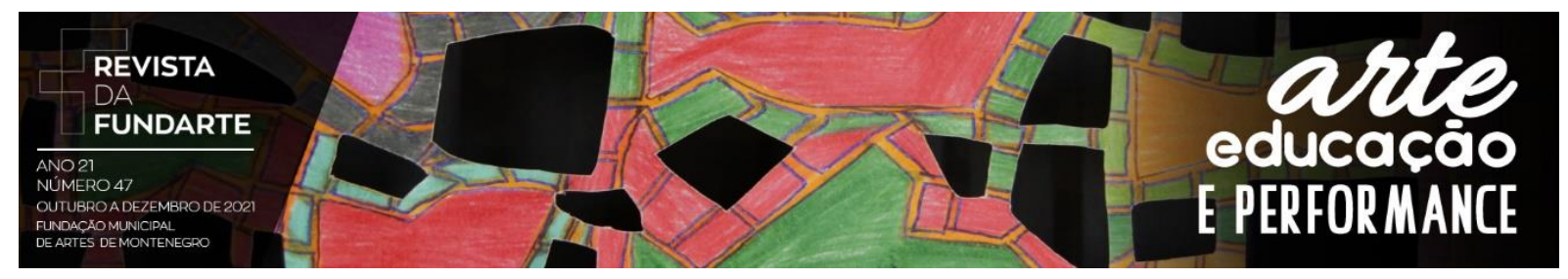

[...] mera serventia ou utilidade, mas como um corpo presente que pode se contrapor ao nosso, criando noções de identidade, posições sociais, ideológicas, relações de poder, entre outras capacidades submersas num corpo inerte, tal como o objeto. (ALMEIDA BATISTA; DA SILVA, 2021, p. 6).

Objetivamente, a porta era o elemento arquitetônico que nos separava do vírus, como se dela para dentro estivéssemos seguros e, dela pra fora, a cidade fosse um grande campo de guerra. Hoje, mais de um ano depois, sabemos que não é exatamente assim que funciona, mas esse era o sentimento que tínhamos na época, como pode ser observado no texto de Albuquerque Júnior (2020, s. p.):

As ruas desertas, já não emitem as mesmas sonoridades estridentes de costume. Apenas uma motocicleta passa furtiva, como que fugindo do inimigo invisível que parece perseguir a todos. Estamos diante de uma paisagem do medo e da angústia, e o silêncio é o signo mais eloquente de que algo se passa, de que algo incomum acontece.

Além disso, pensando de forma mais subjetiva, as portas eram o elemento que representava o momento de inserção da Dança como componente curricular no CAp/UFRGS. O processo de criação dessa área artística de forma independente dentro da escola está recém sendo iniciado e, assim, cada passo que é dado para a definição de movimentos de mudança no currículo é pensado estrategicamente.

O professor de Arquitetura, Fernando Fuão (2016, p. 43), nos ajuda a pensar sobre o que é uma porta. "A porta é sempre um ando, um indo, um estando, nunca se é ou se está realmente na porta, mas caminhando, atravessando." Desta forma, dançar as portas se trata de um rito de passagem (MC THA, 2019), observando aspectos do período anterior à Dança na escola como disciplina e atentando-se a um novo modo de viver, durante e após um período de pandemia.

Experimentamos, eu e algumas colegas professoras de diferentes linguagens artísticas, parceiras na empreitada de inserção da Dança como componente curricular na escola, a abertura de portas, de janelas e de novos caminhos para o ensino da Dança, mas mais do que abrir as portas que estão completamente fechadas, tentamos perceber quais são e onde estão as portas já entreabertas, pois "a abertura sempre aberta, entreaberta, é o que permite o encontro, a reunião, é a porta aberta que faz o lugar, a relação". (FUÃO, 2016, p. 32). Porém, nem sempre estamos completamente abertas para estar em relação 


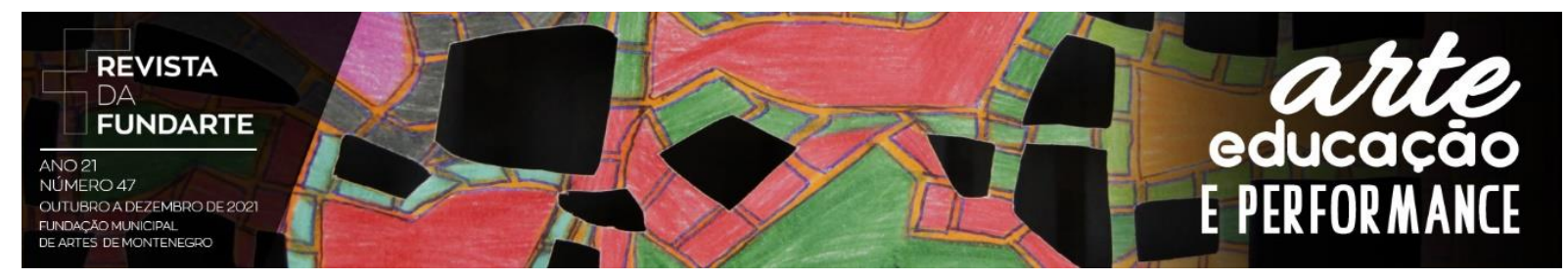

com o contexto escolar, nossa trajetória define nossa forma de atuação e é preciso prestar atenção à que nos abrimos e à que nos fechamos realmente, assim como as portas (FUÃO, 2016).

\section{Ela é a própria porta}

No início do período de distanciamento social, algumas das atividades de Dança propostas por mim giraram em torno da criação artística adaptada ao ambiente privado da casa. Espaços que antes eram só utilitários da moradia, onde não era confortável "estar", viraram espaços dançáveis. Num momento em que habitar a casa era algo fundamental para a compreensão do modo de funcionamento do vírus, a percepção aos elementos arquitetônicos, objetos e lugares que constituem a residência tomou uma grande proporção para mim, visto que possuo uma trajetória de criação artística relacionando dança e espaço.

Tenho graduação em Arquitetura e Urbanismo e em Licenciatura em Dança, além de Mestrado em Arquitetura e Urbanismo e experiência não-formal em grupos de Dança Contemporânea, assim, minha pesquisa artística se encaminhou para a dança na cidade ou dança in situ ${ }^{6}$. Minhas últimas propostas de criação artística estiveram aliadas ao grupo Caminhos da Dança na Rua (Figura 1), que se configurava como um projeto de extensão do curso de Dança-Licenciatura da Universidade Federal de Pelotas, cujo objetivo era experimentar movimentos que surgissem da relação do corpo com os diferentes espaços arquitetônicos e urbanísticos.

\footnotetext{
${ }^{6}$ Dança in situ ou dança site specific é definida por Carmen Morais $(2015$, p. 58$)$ como "o conjunto de criações de dança no qual suas escrituras coreográficas são compostas com as particularidades de um sítio". Há, assim, uma relação intrínseca entre corpo e espaço, onde a cidade não é vista como cenário, mas é "parte integrante e constitutiva da proposição artística".
} 

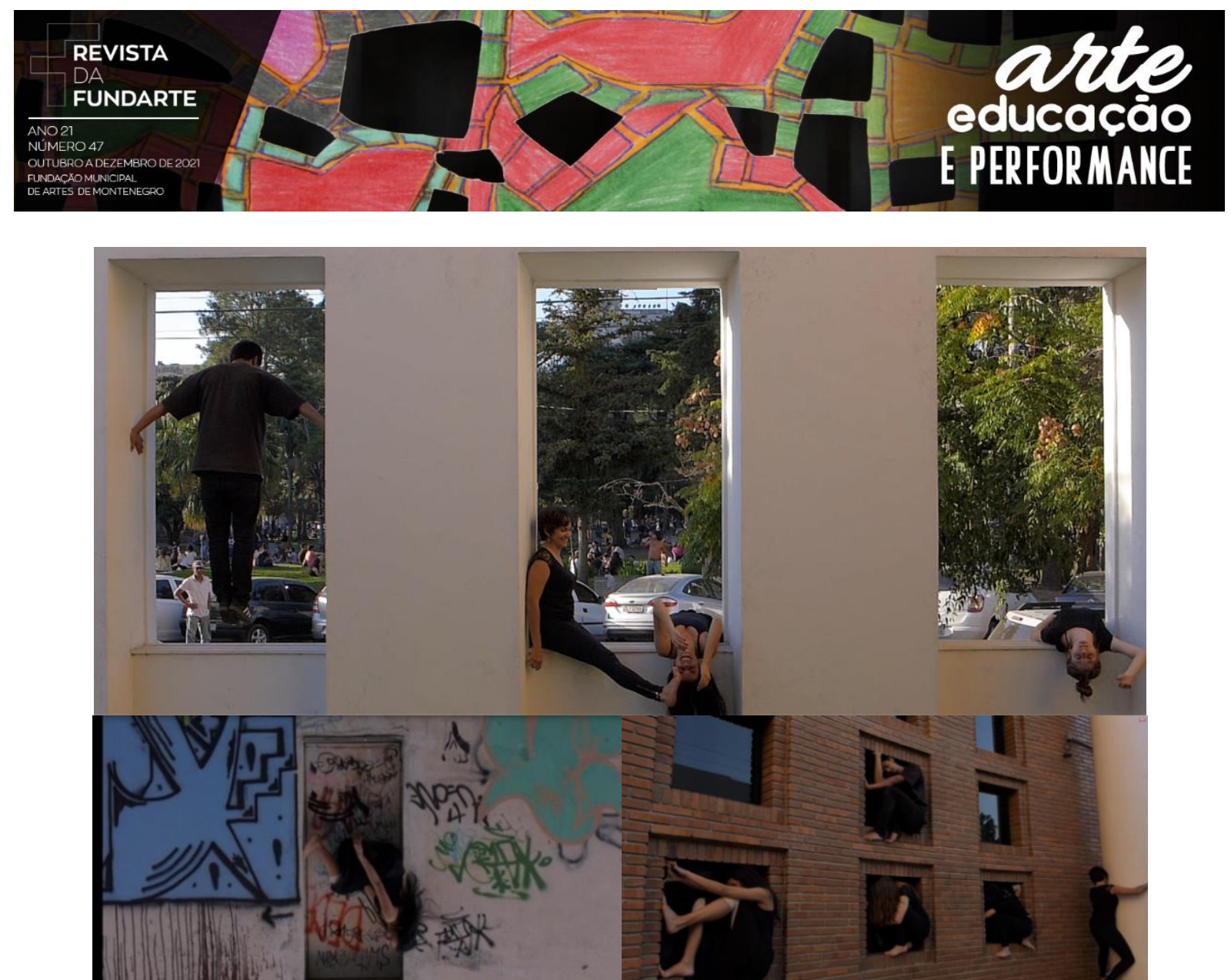

Figura 1: Caminhos da Dança na Rua, em criação a partir de aberturas, portas e paredes. Fonte: Frames do vídeo Incômodas?.

Outro espaço de formação importante para mim foi o Centro Contemporâneo Berê Fuhro Souto, grupo independente de Dança Contemporânea da cidade de Pelotas/RS, que realizava algumas experimentações na rua e também propunha criações situadas, portanto, diversos exercícios propostos pela coordenadora do grupo, Berenice (Berê) Fuhro Souto (1958-2017), trabalhavam o contato do corpo com os elementos arquitetônicos dos locais de ensaio e apresentação. O espetáculo intitulado Da escravidão ao sincretismo: Quatro elementos negros (Figura 2), por exemplo, foi uma ação itinerante, uma visita guiada, no entorno da Biblioteca Pública Pelotense, utilizando a especificidade do lugar como elemento de criação em dança.

\footnotetext{
${ }^{7}$ O vídeo completo está disponível em: $<$ https://www.youtube.com/watch?v=hiLOl4witlw\&t=6s\&ab channel=NozAudiovisual $>$. Acesso em: 30 jul. 2021.
} 

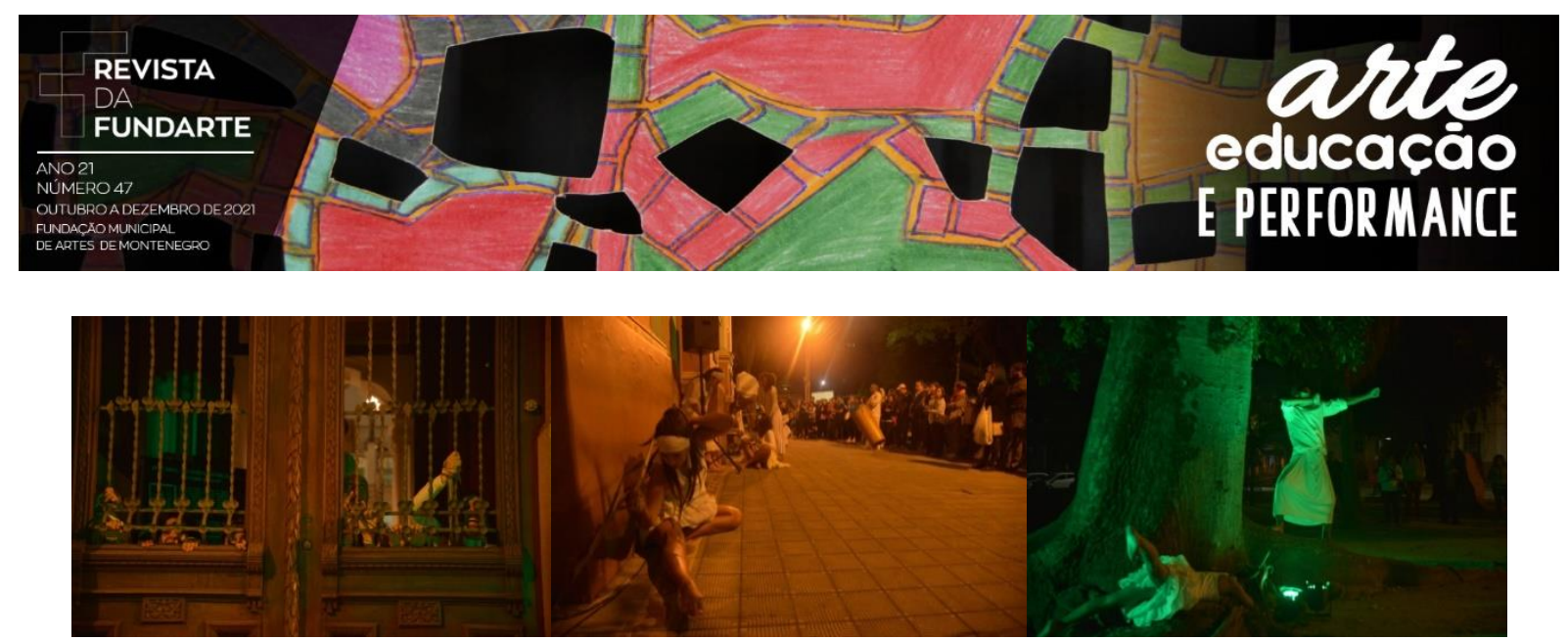

Figura 2: Espetáculo Da escravidão ao Sincretismo: Quatro elementos negros, Centro Contemporâneo Berê Fuhro Souto, 2015, Pelotas/RS. Fotos: Janine Tomberg.

Como se pode verificar nas figuras 1 e 2 , os movimentos de dança são totalmente relacionados ao espaço de apresentação. As paredes, aberturas e elementos naturais são utilizados para o processo criativo das bailarinas. Essas referências, consideradas como experiências do meu passado recente, são inspirações fundamentais para o desenvolvimento da atividade artístico-pedagógica proposta nos Estudos Dirigidos, cujo detalhamento será feito posteriormente, pois tornaram a ser importantes no momento em que o distanciamento social exigiu novos modos de organização espacial para a produção de dança. A respeito da criação artística durante o período de quarentena, Deffaci et. al. (2021, p. 4) colocam:

Parecemos estar, todas, caindo na memória do dentro, no espaço interno de nossa cinesfera física, psicológica, vibracional. O dentro tornou-se um espaço ampliado de produção de si, com o olhar atento às últimas notícias do fora, mais ameaçadoras que acolhedoras.

Portanto, reviver as memórias parece ser um aspecto importante para as autoras da citação acima, assim como tem sido para mim neste contexto. Como forma de sobreviver às incertezas de um período pandêmico, ressalta-se a importância de olhar para dentro de si, assim como se torna fundamental a atualização sobre o que acontece com o resto do mundo, num movimento de viver a realidade como um todo, equilibrando dentro e fora, ora abrindo e ora fechando a porta. E buscando compreender novas formas de criar em dança e novas formas de ensinar a partir do modelo remoto, propus às alunas do Ensino Médio do CAp/UFRGS uma atividade de criação em dança em contato com "a porta", elemento concreto e de acesso irrestrito. 


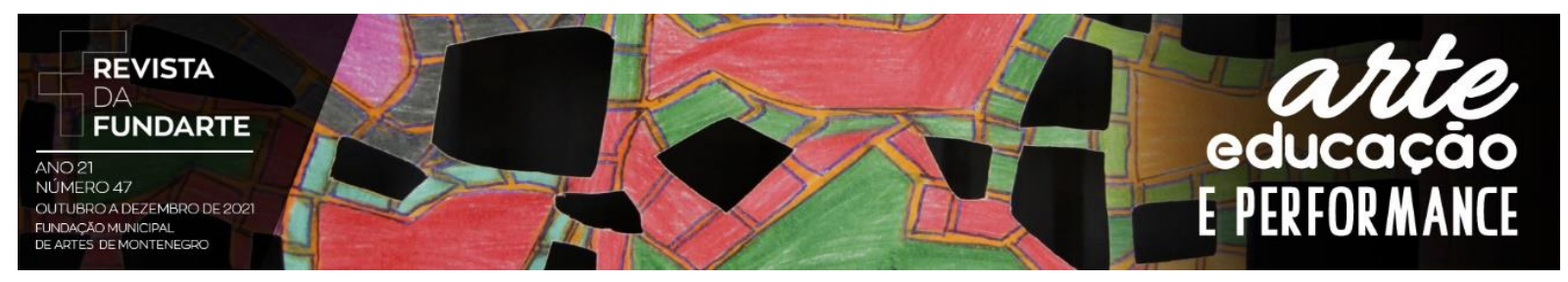

O texto do Estudo Dirigido (Figura 3) iniciava-se por reflexões mais objetivas, sobre o momento atual, de privação de convívio, de "ficar em casa" para a segurança do coletivo, e de outras, mais filosóficas, sobre a porta da casa como metáfora de proteção, e acerca do elemento arquitetônico chamado de "abertura", compreendido como passagem para outra realidade, diferente daquela vivenciada em 2020. Em seguida, era feito o convite à criação e reprodução em dança de forma mais específica.

Título ou conteúdo da tarefa: Qual a porta que me com-porta?

1. Oi gurias! Mudando um pouco o que vínhamos trabalhando... essa semana vamos dançar!!!!! E quero pensar-dançar, junto com vocês, as portas. Vou explicar: Estamos em casa, com as portas fechadas o máximo de tempo possível para nossa segurança. Mas o que mais representam essas portas e o que elas podem nos fazer pensar?

A porta comunica, conecta mas também separa, divide É chegada, saída, espera A porta é movimento, é atravessamento. Janelas e portas se abrem para o exterior ou para o exterior de outro interior. Possibilitam a entrada do sol e produzem sombras. Como diria Marisa Monte, "Portas e janelas ficam sempre abertas pra sorte entrar", mas cuidadol Portas abertas também são risco de contágio... Quem passou por ali? Será que alguém tocou nelas? O que tem na história dessa porta? O que está lá, mas é invisível? Mãos, pés, ombros, cotovelos, joelhos... quais são os movimentos que fazemos para abri-las sem ter contato com o rastro do outro?

Tecnicamente, na arquitetura, elas são chamadas de aberturas. E a MC Tha nos chama para "Cantar e dançar pra saudar. O tempo que virá, que foi, que está. Tocar pra marcar o rito de passá, o rito de passá. Abram os caminhos. Abram-se os caminhos.". Será que esse tempo de isolamento social está abrindo novos caminhos para o mundo?

Vamos dançar a porta? Com a porta? Com-porta.

2. Tarefa: Faça um vídeo de 1 minuto dançando com uma porta interna da sua casa. Nesse vídeo, os $\mathbf{3 0}$ segundos iniciais serão de uma sequência que eu criei e vocês poderão aprender através desse vídeo aqui: https://voutu.be/P0NahaqioA4. Os outros $\mathbf{3 0}$ segundos será criação de vocês. Lembrando que a ideia não é dançar na frente da porta, mas dançar com a porta ou seja, é preciso ter sempre uma parte do corpo encostando na porta. A ideia é fazer uma edição de todos os nossos vídeos (das duas turmas 100 e das duas turmas 200) em um único vídeo (este poderá ser postado e compartilhado ou não, a gente vai decidir isso depois, dependendo de como ficar).

Coisas importantes: A) o vídeo deve ser feito com a câmera parada e em pé (modo retrato) focando a porta toda (ou o máximo possível) - invente um jeito de fazer um tripé com alguns objetos da casa, para que a câmera fique parada. B) o figurino deve ser roupa preta - calça, short ou saia e blusa/casaco de qualquer tipo. De preferência sem nenhuma estampa ou nada escrito. C) se quiserem colocar música, tudo bem, mas na hora da edição eu vou ter que fazer uma montagem com uma música única para todas nós. D) não esqueçam de fazer um aquecimento antes de começar, está ficando friozinho, cuidem para não se machucar. E) repetindo: 30 segundos de coreografia já criada pela prof e 30 segundos de coreografia criada por vocês.

Figura 3: Parte do primeiro Estudo Dirigido que continha a atividade de criação em contato com a porta. Fonte: Arquivo pessoal da professora.

\section{Qual a porta que me com-porta?}

A proposição inicial indicava o aprendizado de uma sequência de movimentos a partir da reprodução/cópia de um vídeo gravado por mim, realizando 


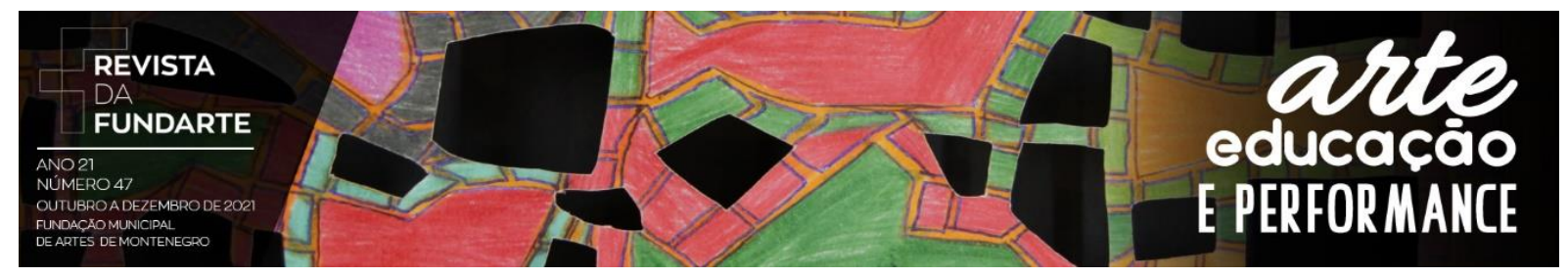

uma criação autoral em contato com a porta ${ }^{8}$. A outra parte da tarefa era a inserção de movimentos criados individualmente por cada estudante da turma ao final da sequência. A ideia era que a criação de movimentos acontecesse no contato "com" a porta, ou seja, era preciso manter pelo menos uma parte do corpo encostada no elemento, para que a criação não ocorresse apenas em frente à porta e sim em diálogo com ela.

A estratégia de criação a partir do corpo em contato com um elemento arquitetônico vertical tem como referência as proposições de criação de Berê Fuhro Souto, que diversas vezes indicava como exercício a improvisação de movimentos em contato com uma parede. A professora e coreógrafa também propunha, nesse exercício, experimentações com a voz, sugerindo que as alunas utilizassem seu instrumento vocal a partir de diferentes qualidades (como com sussurros, falando mais alto, mais grave, a partir de alguma emoção, entre outras), e essas qualidades também deveriam ser transpostas para o corpo em movimento. A principal regra para a improvisação era deixar pelo menos uma parte do corpo em contato com a parede.

A coreógrafa utilizava-se de diversas técnicas e princípios corporais para desenvolver seu método de preparação e criação em dança, dentre elas o contatoimprovisação (GUIMARÃES; ALLEMAND, 2019), um "[...] estilo de movimento que deriva dos duetos e da interação do grupo, mas que pode ser extrapolado e experimentado por um dançarino sozinho." (LEITE, 2005, p. 93). Uma das principais características dessa técnica é que não existem movimentos pré-concebidos a serem aprendidos e o fundamento está em "[...] focalizar na sensação interna do toque, do contato e da pressão do peso dos corpos." (LEITE, 2005, p. 102).

Assim como no contato-improvisação, que realiza alguns exercícios como "[...] encontrar e testar o centro de equilíbrio do corpo, [...] sensibilizar os pontos de contato, [...] e experimentar com uso de objetos e adereços." (LEITE, 2005, p. 104), as proposições que fiz na atividade "Qual a porta que me com-porta?" foram nessa direção, ou seja, de experimentar o equilíbrio corporal e a criação em dança a partir

8 O vídeo está disponível em:
https://www.youtube.com/watch?v=P0NahaqioA4\&ab channel=D\%C3\%A9boraAllemand. Acesso em: 30 jul. 2021. 


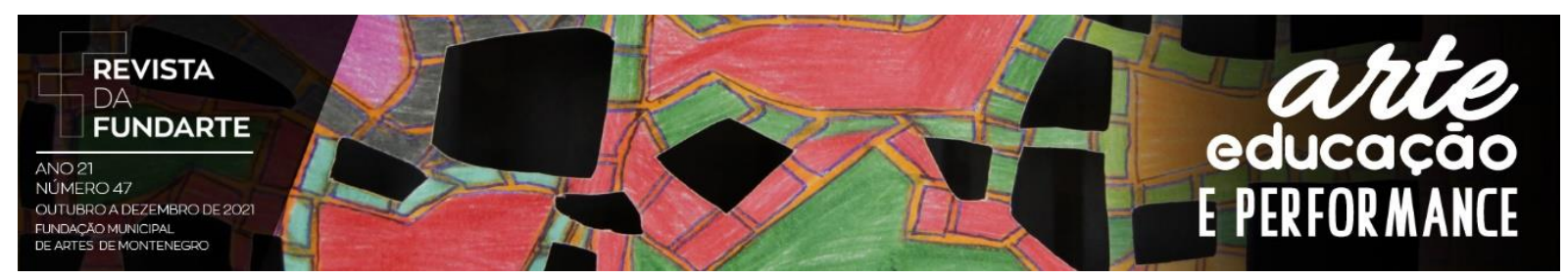

do foco nos pontos de contato do corpo com a porta. As outras regras, que aparecem no documento de maneira informal como "coisas importantes" (Figura 3), estavam mais relacionadas à forma de gravação do vídeo - cuidado às velocidades de cada movimento da sequência, modo de posicionamento de câmera, figurino e tempo total da sequência, com a possibilidade de criar em conjunto com alguma trilha sonora - e não tanto a respeito da improvisação em dança.

O retorno dos primeiros vídeos foi escasso e aqueles que foram recebidos demonstraram pouco envolvimento das alunas nas criações em dança. É possível que isso tenha ocorrido em função da forma como a atividade foi proposta, ou seja, com poucas indicações sobre a parte de criação individual. Segundo Patrícia Silva (2017, p. 60), refletindo sobre um projeto de dança na escola com estudantes de $9 \mathrm{e}$ 10 anos de idade, ficava nítido que as crianças se sentiam desconfortáveis "[...] quando a proposição era: 'vamos criar". A autora supõe que eram raros os estímulos à criação artística para aquelas crianças, o que fazia com que elas tivessem dificuldade nas propostas improvisacionais.

Ainda que se trate de uma faixa etária bastante diversa à do Ensino Médio, e ainda que o CAp/UFRGS seja uma escola com bastante espaço às disciplinas artísticas, é possível que isso também tenha ocorrido com as alunas que cursavam Dança em 2020, em função de esse ter sido o primeiro ano da Dança como componente curricular autônomo na escola. Além da dificuldade na proposta de criação autoral, também houve receio na aprendizagem através da cópia, provavelmente porque as alunas não se sentiam à vontade para a realização de uma sequência de dança com características da dança contemporânea.

Essa questão é apontada também pelo pesquisador Jeferson Cabral (2020), em Tese de Doutorado realizada através de pesquisa-ação no mesmo contexto que o nosso, porém, alguns meses antes da minha nomeação como professora de Dança. O autor observa que os e as estudantes "tinham muita dificuldade de compreender e aceitar a dança contemporânea como dança" (p. 160), demonstrando uma "compreensão restrita de dança por parte da turma" (p. 122). Cabral (2020) aponta que a dança contemporânea trabalhada a partir da improvisação não era o que a turma considerava como dança. 


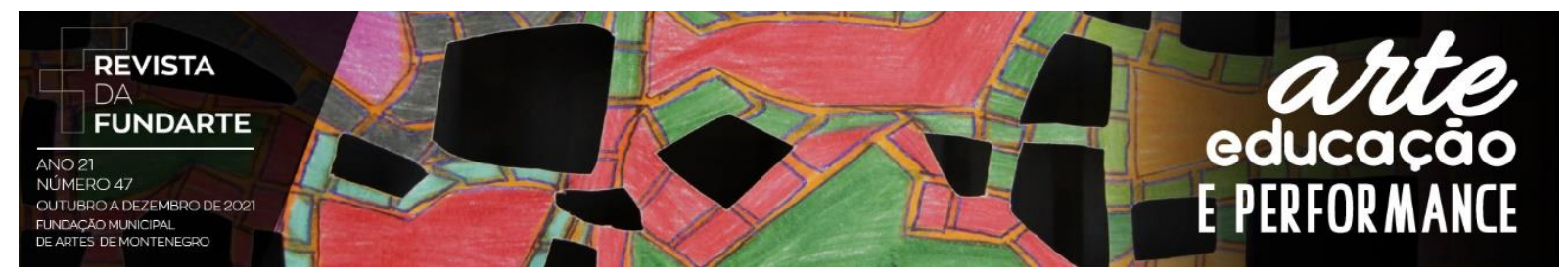

A respeito disso, expomos um diálogo que ocorreu com uma das alunas. Em troca de e-mails, a jovem revela:

Eu não fiz o vídeo da porta porque acho que não me daria bem com o estilo da dança, mas sei que devemos experimentar de tudo. Então queria saber se tu acha muito necessário eu fazer esse vídeo... se sim, posso fazer esta semana e te mandar! (Giulia, 2020, grifo nosso).

Buscando saber mais sobre qual a concepção dela a respeito do "estilo da dança”, questionei sobre qual modalidade ela pensava ser e perguntei por que ela imaginava que não se daria bem dançando com aquelas características e qualidades de movimentos sugeridas no vídeo da coreografia criada por mim. A aluna respondeu falando sobre a velocidade dos movimentos, que são mais calmos, e remeteu o "estilo" a uma coreografia que havia sido proposta por mim no início do ano, ainda nas aulas presenciais. Por fim, ela comentou: "Não sei explicar muito bem, achei super legal a intenção do vídeo com a porta, mas não sei se conseguiria fazer os passos e dançar com a porta ao mesmo tempo, tipo, não teria a facilidade de me movimentar, por exemplo."

Percebendo que a aluna trazia duas dificuldades de diferentes ordens, uma relacionada à aprendizagem da coreografia já definida e outra relacionada à criação em contato com um objeto, propus que a estudante realizasse a tarefa de outra maneira. A sugestão foi de que a aluna aprendesse a sequência, mas que pudesse transformá-la, por exemplo fazendo mais rápido, fora da porta ou em relação a outro elemento. E com relação à criação autoral em contato com a porta, insisti que a movimentação deveria surgir a partir do contato com o elemento vertical, ou seja, que esses movimentos provavelmente não seriam criados se fossem improvisados em outro espaço.

O diálogo entre docente e discente por e-mail surtiu efeito, pois a estudante realizou a proposta. A partir de seu vídeo, é possível observar que ela aprendeu a sequência de movimentos e fez uma proposta de criação justamente a partir desta, ou seja, criou uma nova sequência decompondo os movimentos da coreografia criada por mim, realizando-os de trás para frente, mas com pequenas mudanças de ordenação. 


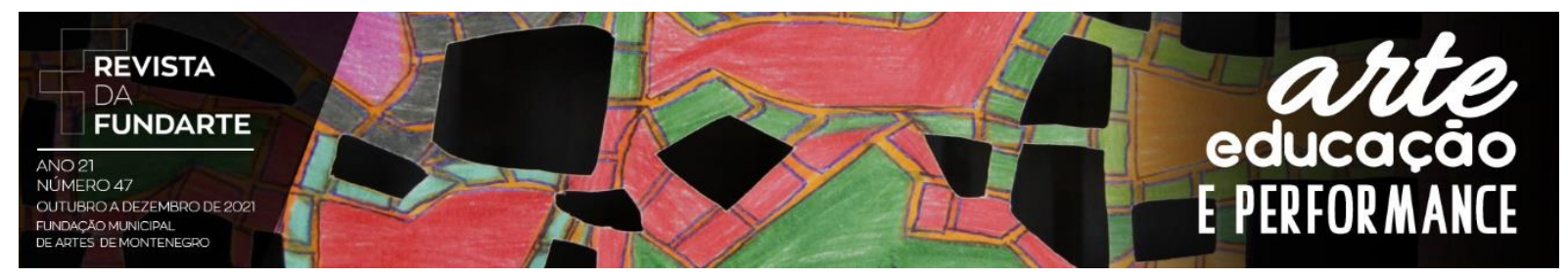

Outra possibilidade aventada, na época, para o acanhado retorno da tarefa, era de que as alunas não tinham conseguido acessar o vídeo no Youtube ou que não tinham acesso aos equipamentos necessários para realizar o trabalho, pois ainda era um período em que estávamos compreendendo de que forma poderíamos ensinar a partir dos Estudos Dirigidos e quais eram as condições e contextos de cada estudante da escola.

Essas constatações motivaram o desdobramento da atividade em outro Estudo Dirigido, na semana seguinte. Como forma de resolver o imaginável problema de acesso ao vídeo, foi feita a decomposição da sequência-base, movimento por movimento, através de imagens. E com relação à dificuldade de criação de uma sequência de movimentos autoral, foram trazidas novas indicações para a pesquisa artística, que agora precisaria abranger: (1) movimentos de abrir e fechar a porta; (2) movimentos onde o foco estivesse nas mãos, dedos e pés; (3) movimentos mais próximos ao chão (nível baixo) e movimentos com o corpo mais vertical (nível alto) e, por fim; (4) movimentos que trabalhassem com o equilíbrio de empurrar-se contra a porta (ficando mais próximo e se distanciando dela) (Figura 4).
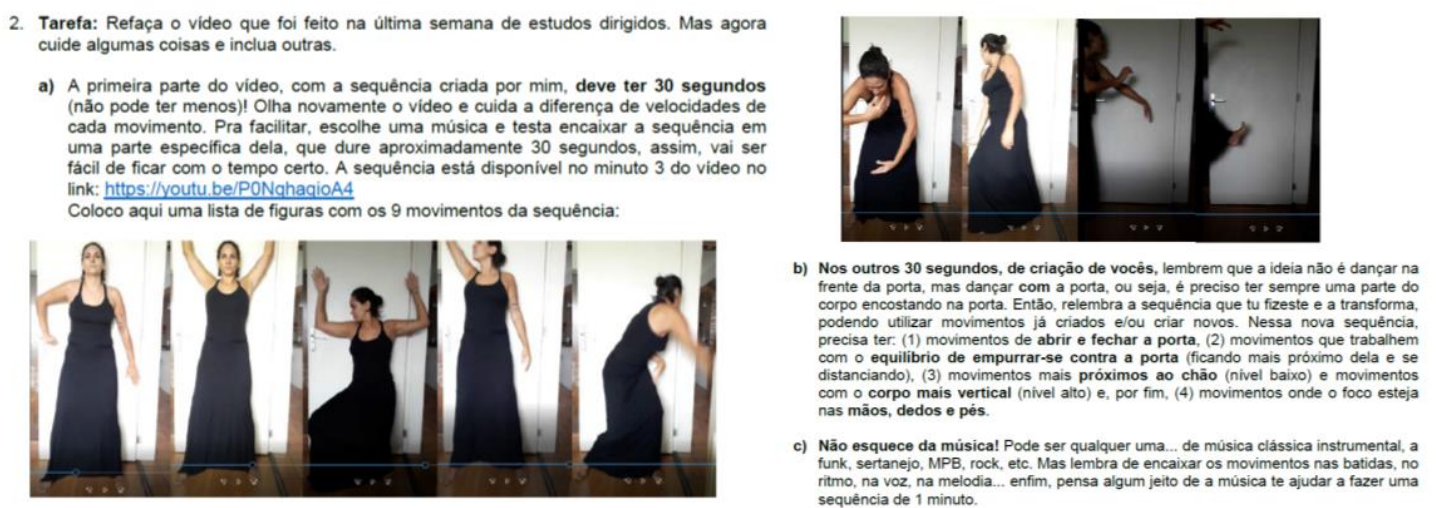

Figura 4: Parte do segundo Estudo Dirigido que continha a atividade de criação em contato com a porta. Fonte: Arquivo pessoal da professora.

Essas últimas indicações-guia para a criação da sequência baseiam-se no sistema de movimento organizado por Rufolf Von Laban (1879-1958). O teórico da dança, que inicialmente estudou Arquitetura na Escola de Belas Artes de Paris, passou a interessar-se pela relação entre o movimento humano e o espaço que 0 circunda, com isso, criou uma teoria de análise do movimento, que inclui o estudo da 


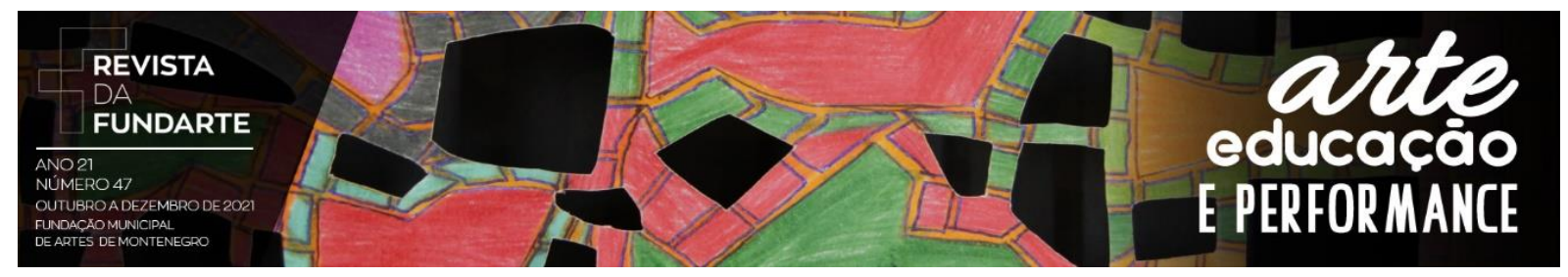

organização espacial e dos aspectos qualitativos do movimento. Uma das organizações didáticas de seu sistema é a Estrela Labaniana, delineada por Valerie Preston-Dunlop (LOBO; NAVAS, 2008). A Estrela é composta por cinco pontas, que são: Corpo, Ações, Espaço, Dinâmica e Relacionamento.

$\mathrm{Na}$ tarefa proposta na segunda semana de criação em contato com a porta, utilizaram-se alguns elementos dos componentes Corpo, Espaço e Dinâmica. Para a compreensão de Corpo, que é observado por partes (como as articulações, superfícies e membros), são quatro as possibilidades de investigação expressiva: congruente e isolado; simétrico e assimétrico; físico e espacial; e central e periférico (LOBO; NAVAS, 2008), sendo a ênfase do nosso exercício nessa última possibilidade, ou seja, a contraposição entre os movimentos com partes centrais e periféricas do corpo.

Em relação ao componente Espaço, são diversas as subdivisões, incluindo o espaço no corpo e o corpo no espaço (LOBO; NAVAS, 2008). No exercício utilizouse somente a ênfase do corpo nos diferentes níveis (alto, médio e baixo), tendo relação direta com o chão. Por fim, na categoria Relacionamento, que seria a forma como a bailarina interage com as outras pessoas, com o espaço, a luz, o cenário ou o público (LOBO; NAVAS, 2008), o foco estava em aproximar ou distanciar-se do objeto, tocando-o e entregando seu peso completamente ou só em parte para a porta.

A partir da teoria de Laban $(1978,1990)$ seria possível desdobrar o exercício outras vezes, inserindo indicações de variação de velocidade, de peso, de fluência, de direções no espaço, incentivando o trabalho com diferentes ações corporais e dando foco ao relacionamento entre as partes do corpo, bem como tratando de questões relacionadas à cinesfera, entre outras indicações para a criação em dança.

Porém, assim como a professora Ana Paula Reis (2021, p. 6), noto que "A falta do contato físico e também das trocas e conversas que temos nas aulas foram fatores que geraram bastante dificuldade na elaboração das tarefas.". O exercício, proposto no início do período de ensino remoto, ainda era uma tentativa de compreender o modo de funcionamento dos Estudos Dirigidos, assim, na dificuldade (ou impossibilidade) de detalhar cada uma das propostas, a simplificação das tarefas 


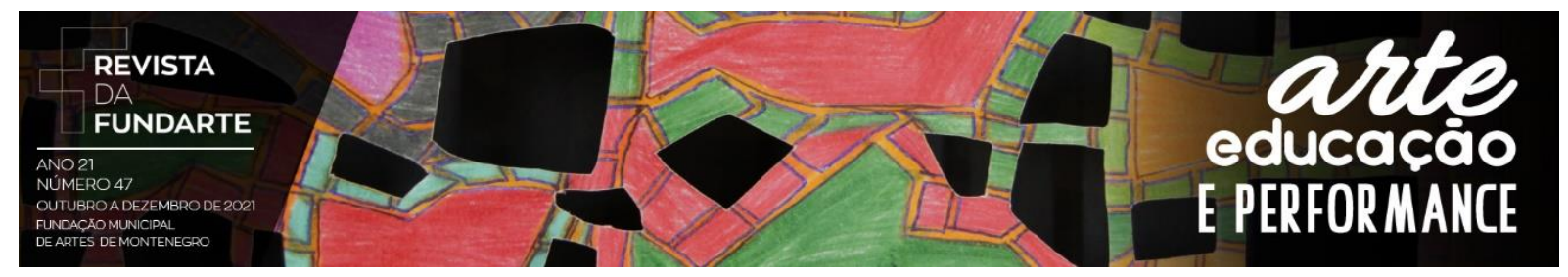

era a forma mais viável para um ensino assíncrono, onde não tínhamos nenhum momento síncrono com as turmas de estudantes para tirar as dúvidas sobre as atividades.

\section{Olhando através do buraco da fechadura}

Após a proposição mais detalhada do exercício de criação, houve um retorno mais intenso por parte das alunas. Os vídeos produzidos pelas estudantes ${ }^{9}$ permitem observar que as indicações objetivas se refletem tanto na compreensão mais apurada da proposição, como na ampliação das possibilidades de criação artística. Porém, pelo material enviado, não é possível saber como foi o processo de criação de cada aluna, pois, diferente de outras propostas que foram feitas durante 0 ano, esta tarefa não incluía questionamentos sobre a realização da atividade ou outras formas de retorno a não ser o vídeo final. Assim, não é possível saber quantas vezes elas experimentaram antes de gravar o vídeo, se utilizaram diferentes portas ou se simplesmente colocaram o celular para gravar, realizaram movimentações e enviaram por e-mail. Esses são segredos que ficarão escondidos atrás das portas (FUÃO, 2016).

Além disso, foi possível compreender um pouco mais do contexto de cada uma das estudantes, como são seus quartos, com quem moram e o que escolhem mostrar, com que partes da casa e com que memórias elas dançam. Algumas só possuem portas de correr em casa, como a Ketelyn, que, por e-mail, expôs a situação, dizendo que isso dificultaria um pouco a execução dos movimentos criados pela professora, mas logo já sugeriu a solução, dizendo que poderia fazer modificando alguns movimentos. Em suas palavras: "Por exemplo, na hora que precisamos abrir a porta de um cômodo para o outro, eu posso adaptar da maneira que eu conseguir?".

\footnotetext{
${ }^{9}$ As produções das alunas foram compiladas numa edição única, fazendo parte da Mostra Virtual de Dança e Teatro do CAp/UFRGS 2020. O vídeo "Qual é a porta que me com-porta" pode ser acessado através do link: $<$ https://www.youtube.com/watch?v=5Nxpk24rkLY\&ab channel=TeatroeDan\%C3\%A7aCol\%C3\%A9giodeAplica\%C3\%A7\%C3\%A3oUFRGS>.
} 


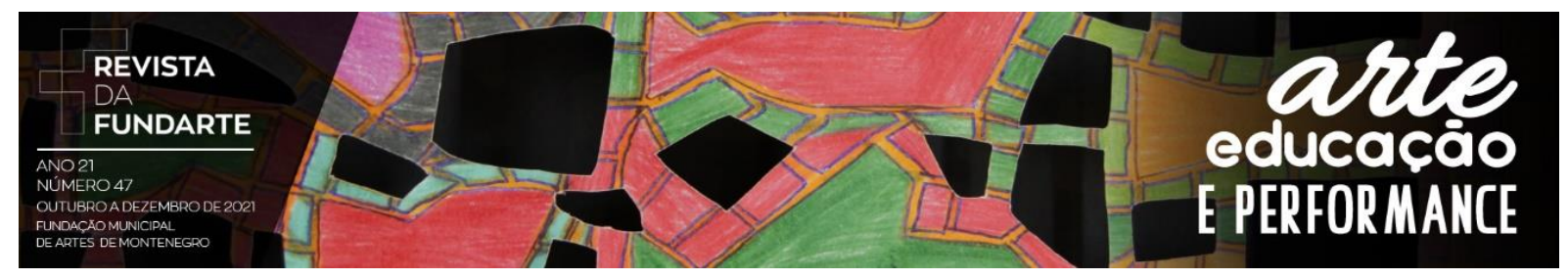

A Julianne é outro exemplo, pois na segunda semana ela não conseguiu realizar a atividade, mas justificou, também por e-mail, dizendo que todas as portas de sua casa estavam com algum impedimento. A aluna completa: "A do meu quarto, que é a que eu usei no outro vídeo, não pode ser usada porque fiz umas obrinhas no meu quarto e tá tudo um tumulto.". Já o último exemplo, que mostra como a atividade foi capaz de revelar os contextos, rotinas e modos de ser das alunas em relação à suas casas, tem foco no ponto de vista que uma das alunas opta por expor, com sua bandeira LGBTQIA $+{ }^{10}$ servindo de cenário para o vídeo (Figura 5).

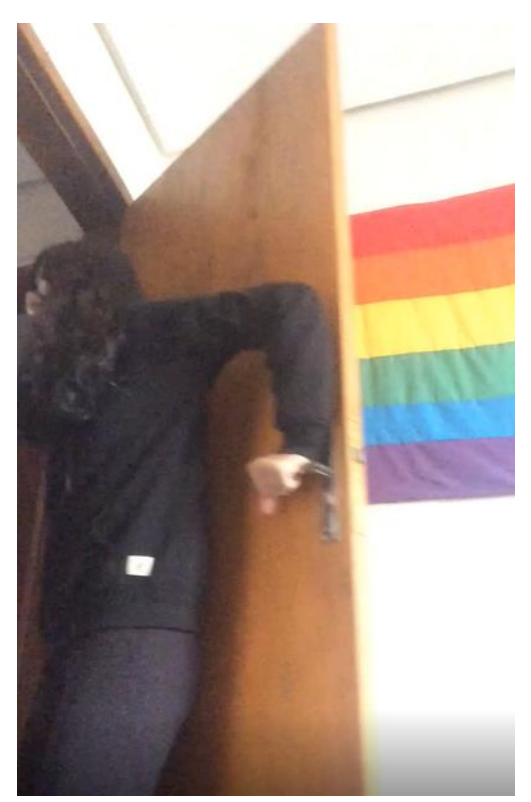

Figura 5: Estudante executando a tarefa proposta e expondo a intimidade de seu quarto. Fonte: Print de vídeo da aluna.

Essas são algumas das questões que tanto o ensino remoto como o ensino de Dança na escola revelam, tal seja, aspectos relativos aos corpos e aos ambientes em que estes estão inseridos. Com relação às imagens de cada movimento da sequência, que foram colocadas no Estudo Dirigido da segunda semana, é possível que tenham auxiliado no acesso à informação, porém, como as alunas enviaram suas atividades através de vídeos, considero que elas possuíam acesso à internet para realizar a visualização do vídeo que havia sido publicado no site Youtube.

\footnotetext{
10 Sigla que representa a comunidade gay. LGBTQIA+ é o movimento político e social que defende a diversidade e busca mais representatividade e direitos para essa população.
} 


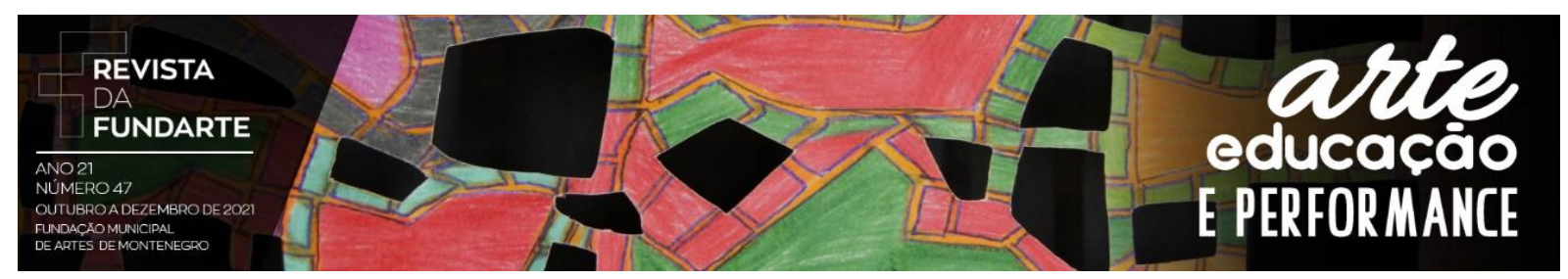

\section{Uma tentativa de fechar as portas}

A porta foi um dispositivo que permitiu reunir uma diversidade de questões que estavam postas para mim no mês de Maio do ano de 2020, dentre elas aspectos do ensino remoto, do distanciamento social e da inserção da Dança no CAp/UFRGS. Assim, a porta serviu como um elemento de "[...] comunicação entre espaços e situações" (FUÃO, 2016, p. 24), em um momento complexo como o início da pandemia de COVID-19. No entanto, conseguir enxergar as portas entreabertas foi o que possibilitou que a caminhada da vida e do ensino de Dança seguisse acontecendo. Olhar para o espaço da casa como o único possível para fazer dança mostrou tanto que é preciso reinventar-se a todo o momento, como que é importante reconhecer nossos repertórios, pois são também eles que nos amparam nos processos de improvisação em dança e no cotidiano.

Apesar de todas as dificuldades, algumas relatadas inclusive pelas próprias alunas e expostas aqui, o período de pandemia também pôde ser visto como um momento de revelação. Neste momento em que realizamos a inserção da Dança como componente curricular no CAp/UFRGS, através de um olhar atento a cada detalhe dos vídeos e a cada palavra trocada por e-mail, passei a conhecer os contextos e referências de dança da comunidade escolar, e mesmo os meus próprios repertórios, passo importante para a abertura de novas portas para o ensino de dança no futuro.

Assim, o ensino remoto, temido e muitas vezes até negado, paradoxalmente me fez atentar para os objetivos da Dança como componente curricular na escola. Porém, somente o ensino presencial é capaz de reunir todas as pessoas num mesmo espaço, atrás de uma única porta, onde o equilíbrio do grupo dependa do contato com o outro, com um corpo que não seja inerte como um objeto, mas com um corpo que possui ideias próprias e que qualquer movimento corporal, mínimo que seja, modifica o movimento do todo. 


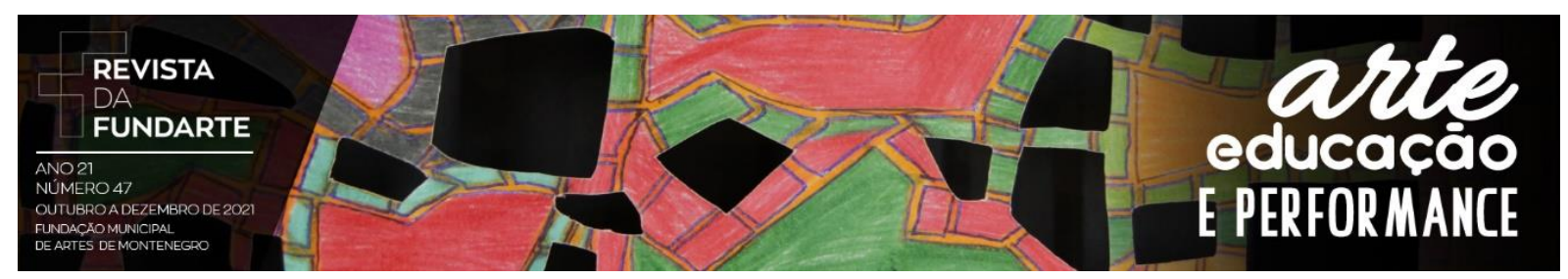

\section{Referências:}

ALBUQUERQUE JÚNIOR, Durval Muniz de. A palavra como luto e como luta. N-1 site Disponível em: <https://n-1edicoes.org/036>. Acesso em: 29 mai. 2020.

ALMEIDA BATISTA, Raphael Junior; Da SILVA, Mariana Silva. Instruções poéticas para se relacionar com objetos cotidianos. Revista da FUNDARTE. Montenegro, p.01-21, ano 21, no 44, janeiro/março de 2021. Disponível em: http://.seer.fundarte.rs.gov.br/index.php/revistadafundarte/index. Acesso em: 30 jul. 2021.

BRASIL. Ministério da Educação. Secretaria de Educação Básica. Conselho Nacional de Educação. Base Nacional Comum Curricular: educação é a base. Brasília: MEC; SEB; CNE, 2017.

CABRAL, Jeferson de Oliveira. Dança-Teatro no Ensino Médio: Uma poética formativa no Colégio de Aplicação da UFRGS. 2020. Tese (Doutorado em Artes Cênicas) - Programa de Pós-graduação em Artes Cênicas, Universidade Federal do Rio Grande do Sul, Porto Alegre, 2020.

CORRÊA, Josiane Gisela Franken. Nós, professoras de Dança: Ensaio documental sobre a docência em Dança no Rio Grande do Sul. 309 f. 2018. Tese (Doutorado em Artes Cênicas) - Programa de Pós-graduação em Artes Cênicas, Universidade Federal do Rio Grande do Sul, Porto Alegre, 2018.

CORRÊA, Josiane Franken. Nem sempre funciona: a dança e a escola. In: CORRÊA, Josiane Franken; ALLEMAND, Débora Souto (Orgs.). Dança na escola: Pedagogias possíveis de sôras para profes. São Leopoldo: Oikos, 2021.

DEFFACI, Kátia Salib; SASTRE, Cibele; PINTO, Aline da Silva; LOPES, Sílvia da Silva. Corpos com(part)ilhados: relatos de um grupo de pesquisa à distância. Revista da FUNDARTE. Montenegro, p. 01-12, ano 21, no 44, janeiro/março de 2021. Disponível em: http://.seer.fundarte.rs.gov.br/index.php/revistadafundarte/index. Acesso em: 27 jul. 2021.

FUÃO, Fernando Freitas. A Porta. FUÃO, Fernando Freitas; VIECELI, Ana Paula (Org.). A porta, a ponte, o buraco, um orelhão. Porto Alegre: UFRGS, 2016.

GUIMARÃES, Miriam Brockmann; ALLEMAND, Débora Souto. Berê Fuhro Souto: pilates e palavra coreografada. Revista da FUNDARTE. Montenegro, p.113-125, ano 19, $\mathrm{n}^{\circ} \quad 37, \quad$ Janeiro/Março. Disponível em: http://.seer.fundarte.rs.gov.br/index.php/RevistadaFundarte/index>. Acesso em: 31 jul. 2021.

LABAN, Rudolf. Dança Educativa Moderna. Tradução: Maria da Conceição Parayba Campos. São Paulo: Ícone, 1990. 


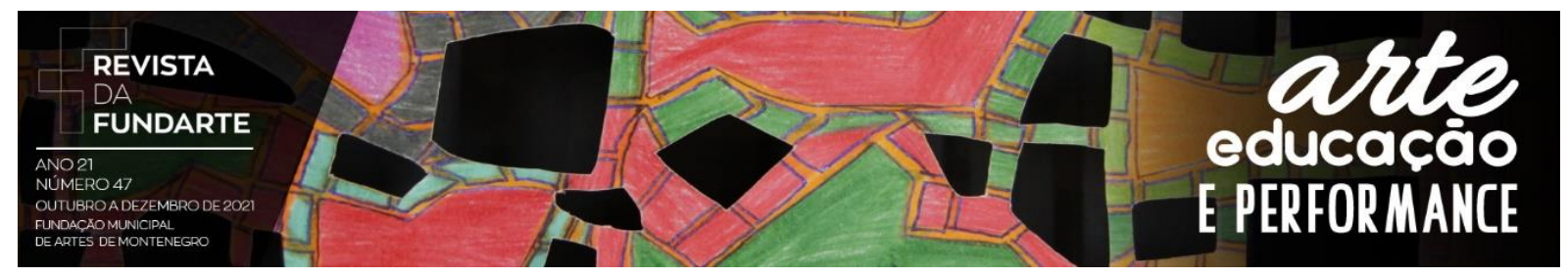

LABAN, Rudolf. Domínio do Movimento. Tradução: Anna Maria Barros de Vechi e Maria Sílvia Mourão Netto. São Paulo: Summus, 1978.

LEITE, Fernanda Hübner de Carvalho. Contato improvisação (contact improvisation): um diálogo em dança. Revista Movimento. Porto Alegre, v. 11, n. 2, p. 89-110, maio/agosto de 2005.

LOBO, Lenora; NAVAS, Cássia. Arte da Composição: Teatro do Movimento. Brasília: LGE Editora, 2008.

MC THA. Rito de Passá. São Paulo: Elemess, 2019. Disponível em: $<$ https://www.youtube.com/watch?v=AJoySdJO9sA>. Acesso em: 17 abr. 2020.

MORAIS, Carmen. A dança in situ no espaço urbano. São Paulo: Lince, 2015.

REIS, Ana Paula. A disciplina de arte no ensino híbrido: possibilidades e desafios nas aulas de dança da rede pública de educação do Estado do Rio Grande do Sul. Revista da FUNDARTE. Montenegro, p. 01-14, ano 21, no 44, janeiro/março de $2021 . \quad$ Disponível em: $<$ http://.seer.fundarte.rs.gov.br/index.php/revistadafundarte/index $>$. Acesso em: 19 mai. 2021.

SILVA, Patrícia Chavarelli Vilela da. Projeto Corpo e $(\mathrm{m})$ Movimento: A criança e a composição em tempo real. In: MUNDIM, Ana Carolina (Org.). Abordagens sobre improvisação em dança contemporânea/Approaches about improvisation in contemporary dance. Tradução: Maria Lyra. Uberlândia: Composer, 2017. 